\title{
Research on the Effect and Influencing Factors of Economic Structure Transition in Jilin Province
}

\author{
Zehao Qiao, Hang Lv, Bishun Lv \\ College of Geography and Ocean Sciences, Yanbian University, Yanji 133000, China
}

\begin{abstract}
After the reform and opening up, Jilin Province, as an old industrial base, had economic development and uncoordinated implementation of the industrial structure. After the "Northeast Revitalization" strategy, the effect of economic transformation was not obvious. The results showed that: (1) The economic structure transformation level of Jilin Province during the study period can be divided into 4 stages: low-level growth stage, slow decline stage, rapid development stage and slow development stage; (2) the main factors affecting the economic structural transformation of Jilin The factors are the scale of openness, the increase or decrease in the development of the secondary industry, and the third level. It is expected to provide theoretical foundation and data support for the transformation of Jilin Province's industrial structure, and promote the accelerated transformation and sustainable development of Jilin Province's economy.
\end{abstract}

Keywords: Economic transformation, Entropy method, Jilin Province.

\section{Introduction}

Economic development is a dynamic process. Each country, region, and region has different influencing factors and interfering factors. These factors will affect or even change the speed and direction of regional economic development, thereby affecting the sustainable development of the region's social economy. The economic structure, especially the industrial structure, is related to the overall economic layout of a region [1], especially in the context of the global economy moving to a higher level, it is particularly important to carry out higher-level industrial structure adjustments. The dual economic theory of W.A. Lewis in the United Kingdom is the most representative[2], and Peter J.G. Pearson puts forward a new way of low-carbon transition[3] based on the viewpoints of many scholars. Kobersy emphasized that realizing the coordinated development of political system, market environment, and economic system is one of the important ways of transformation[4].

Since the actual situation of each country and region is different, the factors that affect its economic structure and economic development are also different. In China, Wu Chongbo[5] first studied the problem of economic structure transformation. Zeng Gang et al. [6] believe that the transformation of industrial structure usually refers to the process of rationalization and efficiency of industrial structure. Meng Ming[7] put forward a decomposition model of the evolution path of resource dependence in the process of economic transformation, and analyzed the change of resource dependence in Shanxi Province from 2006 to 2012. Pei Xiaobing et al.[8] believe that the core of "transformation" is to adjust the economic growth mode. Xu Kun[9] clarified the role of supply-side structural reforms on the high-quality development of my country's economy, and summarized four ways to achieve high-quality economic development. Liu Na et al.[10] used the Super-SBM model to calculate the high-quality development efficiency of China's economy from 2000 to 2017 and analyzed its temporal and spatial evolution characteristics. They believed that the various elements of technological innovation had a strong driving effect on high-quality economic development.

Generally speaking, most scholars believe that the transformation and evolution of economic structure mainly have several characteristics: First, the industrial structure changes from agriculture to industry and then to service industry; second, the type of industry changes from resource-intensive, labor-intensive to capital-intensive. Technology-intensive transformation, the third is the transformation of the industrial structure from low-level to high-level, and the fourth is that with the drive of social and economic development and innovation, different regions have different ability to cope with economic risks, and their internal evolution laws are also different.

As my country's important industrial base in the 1990s, the Northeast region has achieved important development in economic construction. With the continuous deepening of reform and opening up and the continuous transformation of economic and social structure, the economic development of the Northeast region has appeared "Northeast phenomenon" (Figure 1).

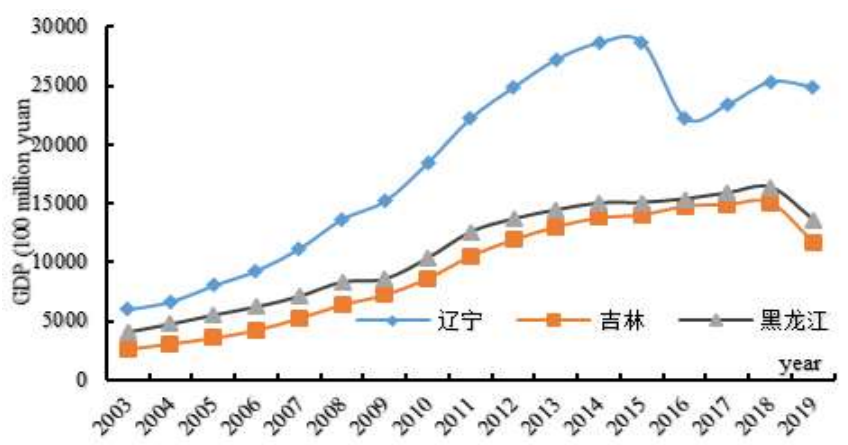

Figure1: Gross National Product of the "Three Eastern Provinces"

In 2003, the Northeast Revitalization Strategy was implemented in the decision-making deployment, and a series of policy support, counterpart assistance and other methods were adopted to promote the rejuvenation of the Northeast region. The economic recession in the Northeast region began 
to reverse, the economic development speed was significantly accelerated, and significant results were achieved. The economic structure is still unreasonable, and the problems facing the Northeast are very serious.

With the country's economic development entering a new normal, especially due to the impact of the new crown pneumonia epidemic in 2020, the downward pressure on the economy of various regions continues to increase. my country's economic growth methods and methods are moving towards high quality. Jilin Province's economic development is facing new problems and difficulties. The original extensive development no longer meets the requirements of today's economic development. With the new normal of national economic development and the normalization of the prevention and control of the new crown pneumonia epidemic, Jilin Province, which is located in the middle of the three northeastern provinces, urgently needs to transform its economic development mode, promote the recovery of high-quality economic development, and transform the original traditional development model to adapt to the country. Changes in the external environment.

Starting from the status quo of Jilin Province, this paper constructs 3 dimensions, 6 first-level indicators, and 20 second-level evaluation indicators. It aims to evaluate the effect of Jilin Province's economic transformation and further identify the factors affecting the effect of Jilin Province's transformation. The transformation of the provincial industrial structure provides theoretical foundation and data support.

\section{Data sources and research methods}

\subsection{Data source}

The main source of the data for this study is the "Statistical Yearbook of Jilin Province 2003-2019".

\subsection{Index system}

The economic transformation of Jilin Province is the result of a long-term and multi-faceted interaction, which not only involves economic and industrial development, but also social progress and environmental improvement. Therefore, the construction of the evaluation index system of the urban economic transformation effect of Jilin Province needs to start from Jilin Province. Starting from reality, constructing an evaluation index system accurately and objectively. When constructing this index system, follow the principles of scientificity, operability, systematization, and purpose. Refer to the research of Li Liangang[11], Wang Fuyao[12], and others Achievements, build an evaluation index system with 3 dimensions, 6 first-level indicators, and 20 second-level indicators (Table 1).

Table1: Evaluation Index System of the Effect of Urban Economic Transformation in Jilin Province

\begin{tabular}{|c|c|c|c|}
\hline System layer & First level indicator & Secondary indicators & Code \\
\hline \multirow{8}{*}{ Economic } & \multirow{4}{*}{ Development } & GDP per capita (Yuan) & $\mathrm{X} 1$ \\
\hline & & GDP growth rate (\%) & $\mathrm{X} 2$ \\
\hline & & Degree of openness (\%) & $\mathrm{X} 3$ \\
\hline & & Business environment (\%) & $\mathrm{X} 4$ \\
\hline & \multirow{4}{*}{ Structure } & Industrialization structure proportion $(\%)$ & $\mathrm{X} 5$ \\
\hline & & Proportion of secondary industry $(\%)$ & $\mathrm{X} 6$ \\
\hline & & Proportion of tertiary industry $(\%)$ & $\mathrm{X} 7$ \\
\hline & & Industry growth $(\%)$ & $\mathrm{X} 8$ \\
\hline \multirow{6}{*}{ Social } & \multirow{4}{*}{ Level } & Urbanization level (\%) & $\mathrm{X} 9$ \\
\hline & & Number of students in colleges and universities (person/ten thousand) & $\mathrm{X} 10$ \\
\hline & & Spending on science and technology as a proportion of GDP (\%) & $\mathrm{X} 11$ \\
\hline & & Number of beds per 10,000 people (pieces $/ 10,000$ people) & $\mathrm{X} 12$ \\
\hline & \multirow{2}{*}{ Live } & Income gap between urban and rural areas (\%) & $\mathrm{X} 13$ \\
\hline & & Engel coefficient (\%) & $\mathrm{X} 14$ \\
\hline \multirow{6}{*}{ Environment } & \multirow{4}{*}{ Life } & Green coverage rate in built-up area $(\%)$ & $\mathrm{X} 15$ \\
\hline & & Water penetration rate $(\%)$ & $\mathrm{X} 16$ \\
\hline & & Gas penetration rate $(\%)$ & $\mathrm{X} 17$ \\
\hline & & Per capita road area $\left(\mathrm{m}^{2}\right)$ & $\mathrm{X} 18$ \\
\hline & \multirow{2}{*}{ Produce } & Comprehensive utilization rate of general industrial solid waste (\%) & $\mathrm{X} 19$ \\
\hline & & Smoke (powder) dust emission intensity (tons/10,000 yuan) & $\mathrm{X} 20$ \\
\hline
\end{tabular}

\subsection{Research Methods}

Construct the evaluation index system of Jilin Province's industrial economic transformation from the perspective of scientific and technological innovation, use the entropy method to analyze, divide the evolution stage of Jilin Province's urban economic transformation on this basis, and conduct a dynamic evaluation of Jilin Province's urban economic transformation. Based on the division, the characteristics of urban economic transformation in Jilin Province at different stages are analyzed with the help of relevant statistical methods.

1) Data standardization processing: The measurement units of the economic development and human settlement environment evaluation indicators selected in this paper are not unified, and the heterogeneous indicators need to be homogenized. Because the various indicators in the indicator system have different directions, the following standardized calculations are used:

$$
\begin{gathered}
Y_{i j}=\frac{X_{i j}-\min \left(X_{j}\right)}{\max \left(X_{j}\right)-\min \left(X_{j}\right)} X_{i j} \text { is the positive index } \\
Y_{i j}=\frac{\max \left(X_{j}\right)-X_{i j}}{\max \left(X_{j}\right)-\min \left(X_{j}\right)} X_{i j} \text { is a negative index }
\end{gathered}
$$

Among them, $Y_{i j}$ is the normalized value, $X_{i j} X_{i j}$ is the original value of the $\tilde{i} i$ item of the $j j$ index, and $\max \left(X_{j}\right) \max \left(X_{j}\right)$ and $\min \left(X_{j}\right)$ are the maximum and minimum values of the index, 
respectively.

2) Calculate the index proportion of the $i$ data under the $j$ index, the formula is:

$$
P_{i j}=\frac{Y_{i j}}{\sum_{i=1}^{n} Y_{i j}}
$$

3) Calculate the information entropy $E_{j}$ of the $j$ index, the formula is:

$$
E_{j}=-k \cdot \sum_{i=1}^{n} P_{i j} \cdot \ln P_{i j}
$$

Where $k=1 / \ln n, 0 \leq E_{j} \leq 1$.

4) Calculate the weight $W_{j}$ of each indicator, the formula is:

$$
W_{j}=\frac{1-E_{j}}{k-\sum_{i=1}^{n} E_{j}}
$$

5) Calculate the comprehensive evaluation index $Z$ :

$$
Z=\sum_{j=p}^{q} W_{j} \cdot Y_{i j}
$$

Calculate the comprehensive evaluation value, let $Z$ be the comprehensive evaluation value of the $j$ year, and its value range is between $[0,1]$. The larger $Z$ is, the higher the level of economic development is. In this paper, the degree of closeness is used to express the comprehensive score of economic development, and the level of economic structural transformation can be judged according to the annual comprehensive evaluation value.

\section{Result Analysis}

\subsection{Comprehensive Evaluation Index}

By calculating the comprehensive evaluation index $Z$ for each year, the Jilin Province Economic Transition Comprehensive Evaluation Index (Figure 2) is obtained. According to the increase or decrease trend of the comprehensive evaluation index, this change can be divided into four stages.

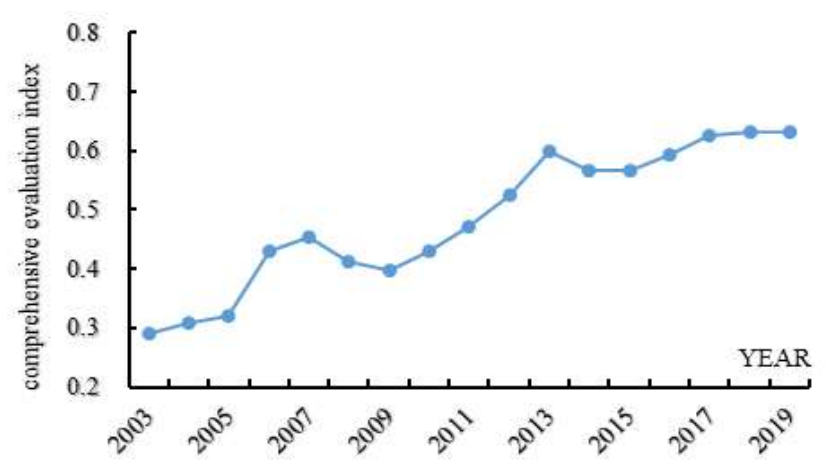

Figure 2: Comprehensive evaluation index of Jilin Province from 2003 to 2019

The first stage is the low-level growth stage. It can be seen from the figure that the overall economic development level from 2003 to 2007 was not high, and the comprehensive evaluation index was below 0.5 , but the index increased year by year. At this stage, Jilin Province has continued to increase its opening up, the total import and export trade volume has continued to grow rapidly, vigorously develop the tertiary industry, and improve the level of urbanization, so that the economy of Jilin Province has achieved rapid development. The industrial structure of Jilin Province has shifted from secondary industry to import and export trade, and certain results have been achieved.

The second stage is the slow decline stage. In 2008 and 2009, compared with the first stage, the comprehensive evaluation index was still not high, and the level of development decreased year by year. In particular, the comprehensive evaluation index in 2008 decreased by 0.041 compared with that in 2007. The main reason for this phenomenon is the global economic crisis that began in late 2007, which greatly reduced the degree of openness of Jilin Province and restricted the business environment. The economic restructuring of Jilin Province has received international restrictions.

The third stage is the rapid development stage. From 2010 to 2013, the comprehensive evaluation index continued to grow rapidly, from 0.431 to 0.599 , the growth rate reached 0.158 , especially in 2012, the comprehensive evaluation index exceeded 0.5 for the first time. At this stage, the tertiary industry has received attention, the degree of industrial growth has been expanding, the income gap between urban and rural areas has been narrowing, and the penetration rate of water and gas has also risen to a certain extent.

The fourth stage is the slow development stage. After 2014, the range of changes in the comprehensive evaluation index of Jilin Province is not very large, but generally still maintains an increasing trend, and the values are all greater than 0.5 . During this period, although Sino-Japanese and Sino-Korea relations were once tense, which led to a decrease in the share of imports and exports and a decline in the degree of opening to the outside world, the proposal of the Northeast Revitalization Strategy prevented the economic decline of Jilin Province to a certain extent. In the context of the Northeast Revitalization Strategy, the proportion of industrialization structure and the proportion of the secondary industry have been decreasing, the proportion of the tertiary industry has been increasing, and the industrial structure has undergone major changes. At the same time, the urban-rural income gap has further narrowed, the number of beds per 10,000 people has increased sharply, and the level of urbanization has continued to rise.

\subsection{Analysis of Influencing Factors}

The weight of each indicator can be obtained by formula (5) in the research method (Figure 3 ). The specific values are as Figure 3 shows.

It can be seen from the Figure 3 that the difference between the weights of the selected 20 evaluation indicators is more obvious, but there is no minimum value, indicating that the selected indicators are all reasonable indicators. Among them, 
the growth rate of regional GDP, the degree of opening up, the proportion of the secondary industry, the degree of industrial growth, the level of urbanization, and the number of beds per 10,000 people play a vital role in the economic development of Jilin Province.

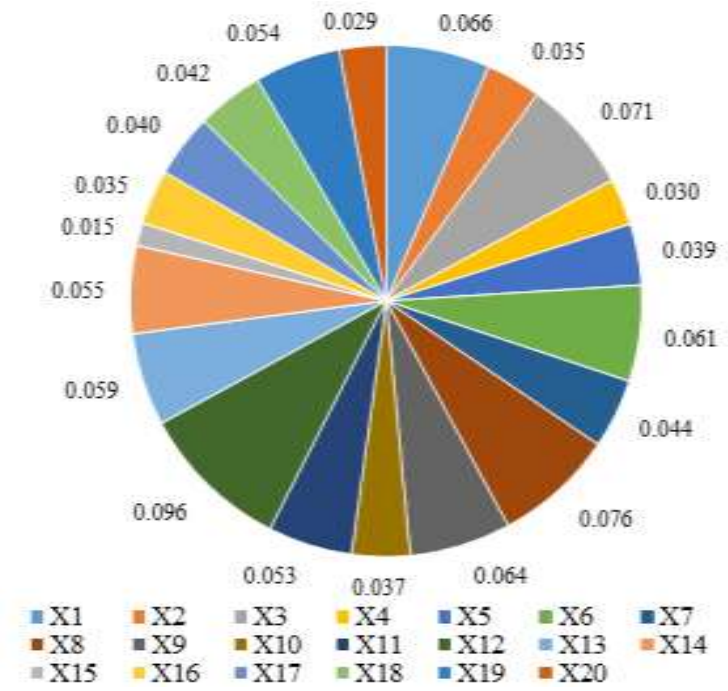

Figure 3: Weights of various indicators

\subsubsection{Regional GDP Growth Rate in Jilin Province}

From 2003 to 2019, under the promotion of the northeast revitalization strategy of Jilin Province, the gross national product of Jilin Province continued to grow, but the growth rate showed different trends in different periods, as shown in Figure 4:

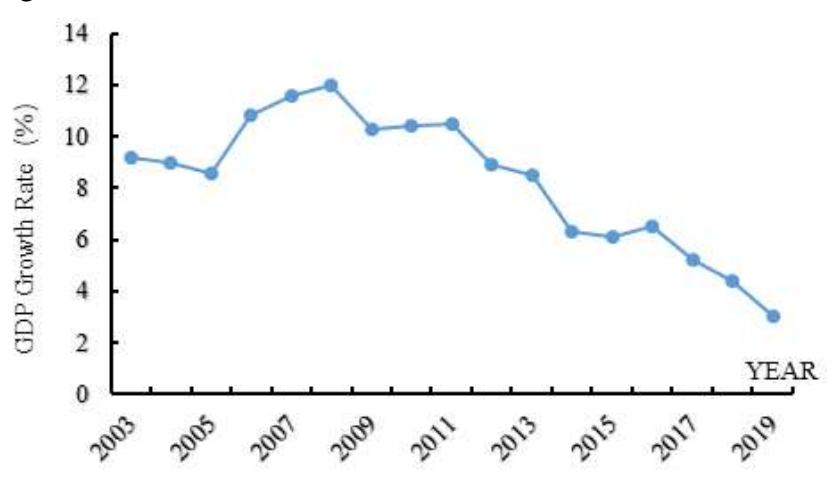

Figure 4: Regional GDP growth rate

From 2005 to 2008, the growth rate increased year by year, but the increase rate decreased year by year, indicating that the Northeast revitalization policy played an important role in the development of Jilin Province in a short period of time. However, after 2008, the growth rate showed a downward trend. Especially after 2015, the total economic volume of the Northeast region experienced a cliff-like decline due to the distortion of the economic structure, the overcapacity of heavy chemical industry, and the backward system. However, the GDP of Jilin Province from 2016 to 2019, the growth rate has declined severely. From a national perspective, the economic slowdown in Jilin Province is the last in the country. The industrial structure is resource-based and heavy-chemical, with serious industrial decline, and the slow development of emerging technologies, emerging industries, and modern service industries. The simplification of the economic structure is prominent, the transformation of resource-based cities is difficult, and many other problems, social pressure on people's livelihood is relatively high, and there is a certain gap between it and the developed regions, and the gap is increasing.

\subsubsection{Degree of opening to the outside world}

The weight value of the degree of opening to the outside world of Jilin Province is 0.071 , which shows that the degree of opening to the outside world of Jilin Province is high or low, and it plays a greater role in evaluating the level of economic development of Jilin Province. From 2007 to 2009, affected by the international economic crisis, the import and export volume of Jilin Province was restricted, which led to a decline in the level of economic development that year.

3.2.3 The proportion of the secondary industry and the degree of industrial growth

The proportion of the secondary industry is an important factor restricting the economic transformation of Jilin Province, and the degree of industrial growth is an important factor in promoting the economic transformation of Jilin Province. It can be seen that the transformation of economic structure is an important way to solve the current economic downturn in Jilin Province.

3.2.4 The level of urbanization and the number of beds per 10,000 people

The level of urbanization is an important factor to measure the level of development of a country. The level of urbanization in Jilin Province has been increasing since 2003, and the number of beds per 10,000 people has also been increasing. This is a decisive factor in the economic development of Jilin Province.

\section{Conclusion}

This paper selects 20 evaluation indicators from the three dimensions of economy, society and environment to construct the evaluation index system of Jilin Province's economic transformation, and uses the entropy method to calculate the comprehensive evaluation index. The results show that: (1) From 2003 to 2019, the economic structure transformation level of Jilin Province can be divided into 4 stages: low-level growth stage, slow decline stage, rapid development stage and slow development stage. (2) The economic development of Jilin Province has encountered bottlenecks in recent years. The only way out is to deepen reforms, expand opening up, and actively adjust the industrial structure to achieve economic structural transformation. (3) The main factors affecting the transformation of the economic structure of Jilin Province are the degree of openness, the increase or decrease in the proportion of the secondary industry, and the level of development of the tertiary industry. The Jilin Provincial Government should seize the opportunity to actively respond to the state's call in an era of major changes unseen in a century. Under the premise of ensuring the healthy development of the secondary industry, the Jilin Provincial 
Government should cooperate with the country in its economic structural transformation and achieve sustained and healthy economic development.

\section{References}

[1] Schumpeter. Economic Development Theory [M]. He Wei, Yi Jiaxiang, et al., translated. Beijing: The Commercial Press, 1990.

[2] Lewis, W.A. Autobiographical Note. Social and Economic Studies[J]. Special Issue in Honour of Sir William Arthur Lewis 1979 Nobel Laureate, 1980, 29(4): 1-10.

[3] Roger Fouquet, Peter J.G. Pearson. Past and Prospective Energy Transitions: Insights from History[J]. Energy Policy, 2012, 50: 1-7.

[4] Shkurkin D, Novikov V, Kobersy I, et al. Investigation of the Scope of Intellectual Services in the Aspect of Virtualization and Information Economy of Modern Russia[J]. Mediterranean Journal of Social Sciences, 2015.

[5] Wu Chongbo. On the Country's Industrial Upgrading[J]. Asia-Pacific Economics, 1988(01): 26-30.

[6] Shang Yongmin, Gang, Hai Jun. Research on China's Economic Growth Mode based on Zengmu's Economic Goals[J]. Resources Science, 2014, 36(05): 937-945.

[7] Meng Ming, Niu Dongxiao, Xu Xiaomin. Research on the Evolution Path Segmentation Model of Resource Dependence in the Process of Economic Transformation[J]. Chinese Management Science, 2016, 24(03): 18-23.

[8] Pei Xiaobing, Pei Zhijie. On Innovation-driven Industrial Transformation and Upgrading[J]. Value Engineering, 2017, 36(06): 84-85.

[9] Xu Kun, Liu Ming. Economic Development: A Paper Report Based on the Research of Chinese Issues [J]. Journal of Lan University, 2021, 37(01): 32-45.

[10] Chen Jingquan, Liu Na, Ma Xiaojun. Measurement of Economic Energy Eco-efficiency of China's Eight Comprehensive Areas and its Driving Factors[J]. Science in China, 2021, 41(05): 2471-2480.

[11] Li Liangang, Zhang Pingyu, Guan Haoming, Tan Juntao. Analysis of the Regional Economic Elasticity Characteristics of Liaoning Old Industrial Base based on Shift-Share[J]. Geographical Research, 2019, 38(07): 1807-1819.

[12] Wang Fuyao. Research on the Industrial Structure Transformation of the Old Northeast Industrial Base under the "New Normal" [D]. Harbin Engineering University, 2018.

\section{Author Profile}

Zehao Qiao (1996-), Graduate student of College of Geography and Ocean Sciences, Yanbian University. Research direction is regional economy and urban development. 